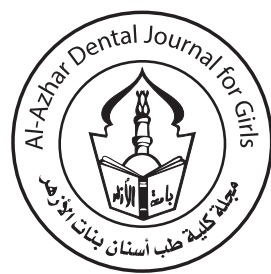

\title{
Effect of Different Superstructure Materials on Peri-implant Clinical and Radiographic Parameters
}

\author{
Ahmed M. Sleem ${ }^{1 *}$, Atef F. Ahmed ${ }^{2}$, Khalid S. Hassan ${ }^{3}$
}

Codex : 04/21.04

azhardentj@azhar.edu.eg

http://adjg.journals.ekb.eg

DOI: 10.21608/adjg.2021.22978.1220

Restorative Dentistry

(Removable Prosthodontics, Fixed

Prosthodontics, Endodontics, Dental

Biomaterials, Operative Dentistry)

\section{KEYWORDS}

Superstructures,

Periodontal parameters,

Marginal bone loss

\begin{abstract}
Purpose: the aim of current study was to assess effect of different superstructure materials on peri-implant periodontal and radiographic parameters at three evaluation periods. Material and Methods: 21 patients with missed lower first molar received delayed dental implant. Patients were divided into three groups to receive 3 different superstructures (monolithic zirconia, zirconia reinforced lithium silicate and polymer infiltrated glass ceramic). Modified bleeding and plaque indices and marginal bone loss were recorded immediately after insertion of superstructures and then after 6,9 and 12 months. Data were tabulated after being collected and analyzed statistically by SPSS version 20. Results: for MPI and MBI, there were no significant differences statistically between any groups for all evaluation periods. MBL increased by the end of the study in all groups. The mean value of MBL in group I was $0.64 \mathrm{~mm} \pm 0.18$ at 6 month that increased to $1.19 \mathrm{~mm} \pm 0.14$ after 12 months. The mean value of MBL in group II was $0.58 \mathrm{~mm} \pm 0.05$ at 6 months that increased to $1.15 \mathrm{~mm} \pm 0.10$ after 12 months. The mean value of MBL in group III was $0.41 \mathrm{~mm} \pm 0.09$ at 6 months that increased to 0.89 $\mathrm{mm} \pm 0.12$ after 12 months. Conclusions: MP and MB indices are mainly influenced by the patient oral care and oral hygiene instructions. The mechanical behavior of superstructure materials, particularly the modulus of elasticity, may influence the stress distribution pattern a round dental implant.
\end{abstract}

\section{INTRODUCTION}

Since dental implants were popularized for the reconstruction of patients in the late 1960s, an attention demand for this form of treatment has increased as it provides conservative treatment modality and

- Paper extracted from PHD thesis titled: "Effect of Different Superstructure Materials on Peri implant Clinical and Radiographic Parameters".

1. Assistant Lecturer of fixed prosthodontic, Faculty of Dental Medicine, Al-Azhar University (Assuit Branch), Egypt. Email: ahmedsleem721@gmail.com

2. Professor and Head of crowns and bridges Department, Faculty of Dental Medicine for girls Al Azhar University.

3. Professor of Oral Medicine and Periodontology, Faculty of Dental Medicine Al-Azhar University (Assuit Branch).

* Corresponding author email: ahmedsleem721@ gmail.com 
durable results ${ }^{(1)}$. Preservation and maintenance of healthy tissues around dental implants is one of the most important factors for successful and durable results. A direct relationship was found between aggregation of dental plaque and the presence of inflammatory changes in the periodontal tissues around oral implants (2). If treatment of such inflammatory condition is neglected, it may lead to a progressive destruction of the implant supporting periodontal tissues compromising its future and finally lead to its failure ${ }^{(3)}$.

Another critical factor for maintenance of durable successful implant-prosthetic system, among many other factors, is the pattern through which stress is distributed in the implant components ${ }^{(4)}$. The stress distribution relies on the fixtures and abutments design, superstructure material and design, the position and location of the implant fixture and quantity and quality of the supporting bony structure $^{(5-7)}$.

Unlike natural dentition, there is no cushion like effect between osseointegrated dental implant and the surrounding bone due to absence of periodontal ligaments which has mechanoreceptors and distribute the applied load favorably. Therefore, the supporting bony structure around dental implants are more porn to resorption particularly at the marginal crest due to stress concentration which is greater at the implant collar ${ }^{(8)}$. Because of absence of such micro-movement of osseointegrated dental implants, most of the functional load is concentrated on the alveolar ridge crest, and this may result in bone resorption with subsequent failure of dental implant. It has been advised that load absorbing or stress damping systems be integrated into the superstructures supported by osseointegrated dental implant, to reduce loading on the implant with subsequent induced bone resorption due to the lack of viscoelasticity at the implant-bone interface ${ }^{(9)}$.

Superstructure materials greatly affect stress distribution and force transfer to surrounding bone. Superstructures with high elastic modulus (as Zirconia and ceramic) transfer great values of the applied load to surrounding bone. In comparison, resinous materials which have low elastic modulus decrease the transmitted load to surrounding bone by about $90 \%{ }^{(10)}$. In other words, resinous superstructures will absorb the occlusal transmitted load and reduces its magnitude on the implant-bone interface $^{(11)}$.

Circumferential bone loss evaluation around dental implants by using dental radiographs has been frequently used in routine dental practice to follow up treatment success or failure and assure favorable and long-term results. It was suggested that a dental implant can be considered successful if the peri-implant alveolar bone resorption didn't exceed $1.5 \mathrm{~mm}$ after one year of implant insertion, and the progressive annual bone resorption didn't exceed $0.2 \mathrm{~mm}^{(12)}$. So, this clinical study was performed to evaluate the effect of three different superstructure materials on peri implant clinical and radiographic parameters.

\section{MATERIAL AND METHODS}

This study included twenty one systemically healthy patients with missed lower first molar motivated to implant placement. All procedures were explained for all patients and written assents were obtained from all patients before performing any study procedures. The study protocol was accepted by the ethical committee, Faculty of Dental Medicine for girls, Al Azhar University.

\section{Clinical and radiographic assessment}

Medical and dental histories were recorded for all patients followed by thorough and clinical extra-oral and intra-oral examination. Standardized periapical radiographs of the implant site by RVG (Ez Sensor HD, Vatech, Korea) were taken. Preoperative CBCT (New Tom GIANO, CeflaDental, Imola (BO), Italy) was done to all patients before surgical procedures to determine supporting bone quality and quantity and to determine the locations of vital anatomical features. 


\section{Presurgical preparation:}

Supportive periodontal therapy was done following clinical examination as required. Oral hygiene instructions and reinforcement were performed at the end of the appointment.

\section{Surgical procedures:}

After administration of local anesthesia, a midcrestal incision was done followed by reflection of a full thickness mucoperiosteal flap. Using implant motor (Surgic XT, NSK, Japan), pilot drilling was performed with a 2.2-mm-diameter pilot drill at the planned implant site. Preparation of each implant site was continued with enlarging drills corresponding to different implant size and length. The implant (Superline Dentium, Seoul, Korea) was inserted until bone level. The final wound closure was performed by interrupted 3/0 sterile synthetic absorbable sutures. Patients were recalled after 14 days for sutures removal.

After 4 months of surgery, patients were recalled back, cover screws were removed and healing caps were inserted. After 3 weeks the patients were recalled back for insertion of definitive abutments and impression making.

\section{Patients grouping and randomization:}

Patients were classified randomly into the following equal groups: Group I, seven patients received zirconia crown as a definitive prosthesis. Group $\Pi$, seven patients received zirconia reinforced lithium silicate crown (vita suprinity) as a definitive prosthesis. Group III, seven patients received polymer strengthened ceramic (vita enamic) crown as a definitive prosthesis.

\section{Impression making:}

The healing abutment was unscrewed. A long transfer coping was screwed on the implant fixture in a clockwise direction. A window opening was cut on a plastic stock tray corresponding to the implant location to allow clearance for the transfer coping.
A light bodied addition silicone impression material (Presdent, Colten, Waledent AG, Switzerland) was injected around the transfer coping while the customized tray was filled with heavy bodied material and seated in the mouth. After setting of impression, the transfer coping was just unscrewed keeping it in place and impression tray was removed with the transfer coping and kept aside. The healing abutment was screwed back onto the implant. Implant analog was hand screwed to the transfer coping and impression, bite registration, opposing impression, and recorded restoration shade were sent to the dental laboratory.

The impression with the connected transfer coping was poured with extra hard dental stone and allowed to set. After which, the transfer cap was unscrewed and titanium based was screwed in place and checked for proper fit in the analog. The flat surface of the base was oriented buccally (not adjacent to the proximal tooth) and any contact between the titanium base and the proximal teeth was avoided. The abutment was sprayed with scanning spray (Renfert Scanspray, GmbH, Hilzingen, Germany). Upper and lower casts scanning was carried out with in lab scanner (CeraMill map400, Amann Girbach, Germany). Suprastructures designing were carried out with software (CeraMill Mind, Amann Girbach, Germany). Milling was carried out with in lab milling machine (CeraMill Motion 2, Amann Girbach, Germany).

For zirconia crowns: Dry milling for zirconia blank (Dmax Multilayer Hybrid, Gwangju, Korea) was carried out. Zirconia crowns were then separated from the blank. Sintering was carried out in sintering furnace (CeraMill Therm, Amann Girbach, Germany) according to manufacture instructions. After finishing, characterization and glazing was done in firing furnace (VACUMAT 6000 , VITA Zahnfabrik, Germany) as reported by manufacture instructions. Abutment was seated onto model and screwed into place on cast. After which, Teflon tape was placed into screw access hole of abutment and Dual cure adhesive resin (TOTAL C-RAM, Itena, Paris, France) with 
auto-mix tip was used to place cement into intaglio of crown and crown was seated on abutment and Teflon tape was immediately removed from hole any excess around hole was cleaned and light cured. Crown with abutment was removed from model to be screwed on the fixture.

For vita suprinity crowns: Wet milling for zirconia strengthened lithium silicate (Vita Suprinity, VITA Zahnfabrik, Germany) crowns were carried out. Fine-grit diamond abrasive tools were used for contouring after the CAM process and finishing diamonds were used for polishing. Prior to crystallization, the restorations were cleaned with the steam jet. The restorations were crystallized according to manufacture crystallization program and glazed in a vacuum furnace that supports slow cooling. Teflon tape was inserted in the hole of abutment screw space to prevent the cement from closing screw opening. The fitting surfaces of crowns were acid etched using hydrofluoric acid gel (DENTOBOND, Itena, Paris, France) for 20 seconds. Silane (DENTOBOND, Itena, Paris, France) was applied for 60 seconds. Dual cure adhesive resin with auto-mix tip was used to place cement into intaglio of crown and crown was seated on abutment and Teflon tape was immediately removed and excess was cleaned and light cured. Crown with abutment was removed from model to be screwed on the fixture.

For vita Enamic crowns: After wet milling for polymer infiltrated glass ceramic crown (VITA Enamic, VITA Zahnfabrik, Germany), diamond tool with water and slight pressure was used to remove the sprue. Sof-Lex polishing discs were used for pre-polishing, only the medium grain (M) and very fine grain (SF) types were used. Contouring and polishing were carried out. The fitting surface of restoration was etched with hydrofluoric acid for 60 sec and salinized subsequently. Dual cure adhesive resin with auto-mix tip was used to place cement into intaglio of crown and crown was seated on abutment and Teflon tape was immediately removed and excess was cleaned and light cured. Crown with abutment was removed from model to be screwed on the fixture.
Definitive prosthesis was tightened using $35 \mathrm{~N} /$ $\mathrm{cm}$ torques. Cotton pellet was applied over screw and finally screw openings were sealed using light cured composite resin.

\section{Periodontal and radiographic evaluation:}

The following parameters were recorded for all implants at the time of final prosthesis insertion and then at 6,9 and 12 months:

\section{Modified plaque index (MPI). ${ }^{(13)}$}

MPI used to determine dental plaque accumulation around marginal area. Modified plaque index recording was as following: 0 (no plaque detected), 1 (plaque recognized only by running a probe along margin), 2 (plaque visible to naked eye) and 3 (abundance of soft matter).

\section{Modified bleeding index (MBI). ${ }^{(13)}$}

MBI used to assess the degree of gingival bleeding around implants. Modified bleeding index included; 0 (no bleeding when probe is passed along margin), 1 (visible isolated bleeding spot), 2 (confluent bleeding red line around margin) and 3 (heavy bleeding).

\section{Radiographic evaluation}

Marginal bone resorption was measured using CBCT that were taken at the time of final prosthesis insertion (baseline) and then at 6,9 and 12 month (Fig1).

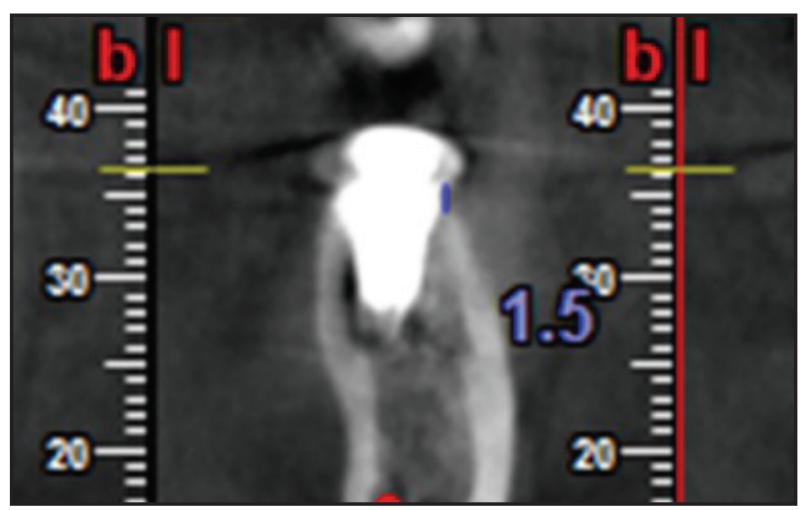

Figure (1) Marginal bone loss measurements 


\section{Statistical Analysis}

The mean and standard deviation values were calculated for each group in each test. Data were explored for normality using KolmogorovSmirnov and Shapiro-Wilk tests. MBL data showed parametric distribution, while MPI and MBI data showed non-parametric distribution.

For parametric data; repeated measure ANOVA was used to compare between more than two groups in related samples. Paired sample t-test was used to compare between two groups in related samples. One-way ANOVA followed by Tukey post hoc test was used to compare between more than two groups in non-related samples. Two-way ANOVA test was used to test the interactions between different variables.

For non-parametric data; Friedman test was used to compare between more than two groups in related samples. Wilcoxon test was used to compare between two groups in related samples. Mann Whitney test was used to compare between two groups in non-related samples. Kruskal Wallis test was used to compare between more than two groups in nonrelated samples.

The significance level was set at $\mathrm{P} \leq 0.05$. Statistical analysis was performed with IBM $®$ SPSS $®$ Statistics Version 20 for Windows.

\section{RESULTS}

\section{Changes in MPI and MBI scores:}

The mean and standard deviation values for MPI and MBI are listed in table 1 and table 2 respectively. Plaque accumulation and gingival bleeding degree were increased by the end of observation period in all groups. No statistically significant alteration was found between any of groups at all evaluation periods.

Table (1): The mean, standard deviation (SD) values of MPI of different groups.

\begin{tabular}{|c|c|c|c|c|c|c|c|}
\hline \multirow{3}{*}{ Variables } & \multicolumn{7}{|c|}{ MPI } \\
\hline & \multicolumn{2}{|c|}{ Group I } & \multicolumn{2}{|c|}{ Group II } & \multicolumn{2}{|c|}{ Group III } & \multirow{2}{*}{ p-value } \\
\hline & Mean & SD & Mean & SD & Mean & SD & \\
\hline Baseline & 0.00 & 0.00 & 0.00 & 0.00 & 0.00 & 0.00 & $1 \mathrm{~ns}$ \\
\hline $6 \mathrm{~m}$ & 0.29 & 0.22 & 0.21 & 0.30 & 0.39 & 0.32 & $0.489 \mathrm{~ns}$ \\
\hline $9 m$ & 0.50 & 0.20 & 0.32 & 0.24 & 0.43 & 0.37 & $0.420 \mathrm{~ns}$ \\
\hline $12 \mathrm{~m}$ & 0.61 & 0.32 & 0.46 & 0.30 & 0.57 & 0.37 & $0.716 \mathrm{~ns}$ \\
\hline p-value & \multicolumn{2}{|c|}{$<0.001 *$} & \multicolumn{2}{|c|}{$0.008 *$} & \multicolumn{2}{|c|}{$0.006^{*}$} & \\
\hline
\end{tabular}

Significant at $p<0.05 \quad$ ns; non-significant at $p>0.05$

Table (2): The mean, standard deviation (SD) values of MBI of different groups.

\begin{tabular}{|c|c|c|c|c|c|c|c|}
\hline \multirow{2}{*}{ Variables } & \multicolumn{9}{|c|}{ MBI } \\
\cline { 2 - 9 } & \multicolumn{2}{|c|}{ Group I } & \multicolumn{2}{c|}{ Group II } & \multicolumn{2}{c|}{ Group III } & p-value \\
\cline { 2 - 9 } & Mean & SD & Mean & SD & Mean & SD & \\
\hline Baseline & 0.00 & 0.00 & 0.00 & 0.00 & 0.00 & 0.00 & $1 \mathrm{~ns}$ \\
\hline $\mathbf{6 m}$ & 0.18 & 0.19 & 0.14 & 0.20 & 0.18 & 0.19 & $0.887 \mathrm{~ns}$ \\
\hline $\mathbf{9 m}$ & 0.39 & 0.32 & 0.29 & 0.09 & 0.36 & 0.24 & $0.708 \mathrm{~ns}$ \\
\hline $\mathbf{1 2 m}$ & 0.57 & 0.37 & 0.50 & 0.32 & 0.54 & 0.30 & $0.921 \mathrm{~ns}$ \\
\hline p-value & \multicolumn{3}{|c|}{$0.003 *$} & \multicolumn{2}{|c|}{$0.001 *$} & & \\
\hline
\end{tabular}

Significant at $p<0.05 \quad$ ns; non-significant at $p>0.05$ 


\section{Changes in Marginal bone level (MBL) Measurements:}

Bar charts representing MBL values for all groups are shown in (fig 2). The results of Two-way ANOVA for the interaction between group and time on MBL are shown in table 3.

MBL increased by the end of the study in all groups. The mean value of MBL in group I was $0.64 \mathrm{~mm} \pm 0.18$ at 6 month that increased to $1.19 \mathrm{~mm} \pm 0.14$ after 12 months. The mean value of MBL in group II was $0.58 \mathrm{~mm} \pm 0.05$ at 6 month that increased to $1.15 \mathrm{~mm}$ \pm 0.10 after 12 months. The mean value of MBL in group III was $0.41 \mathrm{~mm} \pm 0.09$ at 6 month that increased to $0.89 \mathrm{~mm} \pm 0.12$ after 12 months.

For all evaluation periods: A statistically significant alteration was found between Group III and each of Group I and Group II where $(\mathrm{p}<0.05)$. While No statistically significant difference was found between Group I and Group II ( $\mathrm{p}>0.05)$.

The results of Two-way ANOVA for the interaction of different variables on MBL showed that groups had a statistically significant effect at $\mathrm{P}$-value $<0.001$. Time had a statistically significant effect at P-value $<0.001$. The interaction between the two variables had no statistically significant effect at P-value 0.429.

Table (3): Results of Two-way ANOVA for the effect of different variables on $M B L$

\begin{tabular}{|c|c|c|c|c|c|}
\hline Source & $\begin{array}{c}\text { Type III } \\
\text { Sum of } \\
\text { Squares }\end{array}$ & df & $\begin{array}{c}\text { Mean } \\
\text { Square }\end{array}$ & F & Sig. \\
\hline $\begin{array}{c}\text { Corrected } \\
\text { Model }\end{array}$ & $7.794^{\mathrm{a}}$ & 11 & .709 & 58.524 & .000 \\
\hline Intercept & 36.696 & 1 & 36.696 & 3030.845 & .000 \\
\hline Groups & .981 & 2 & .490 & 40.501 & .000 \\
\hline Time & 6.741 & 3 & 2.247 & 185.578 & .000 \\
\hline $\begin{array}{c}\text { Groups * } \\
\text { Time }\end{array}$ & .073 & 6 & .012 & 1.005 & .429 \\
\hline Error & .872 & 72 & .012 & & \\
\hline Total & 45.362 & 84 & & & \\
\hline $\begin{array}{c}\text { Corrected } \\
\text { Total }\end{array}$ & 8.666 & 83 & & & \\
\hline
\end{tabular}

$d f$ : degrees of freedom $=(n-1), *$ Significant at $P \leq 0.05$

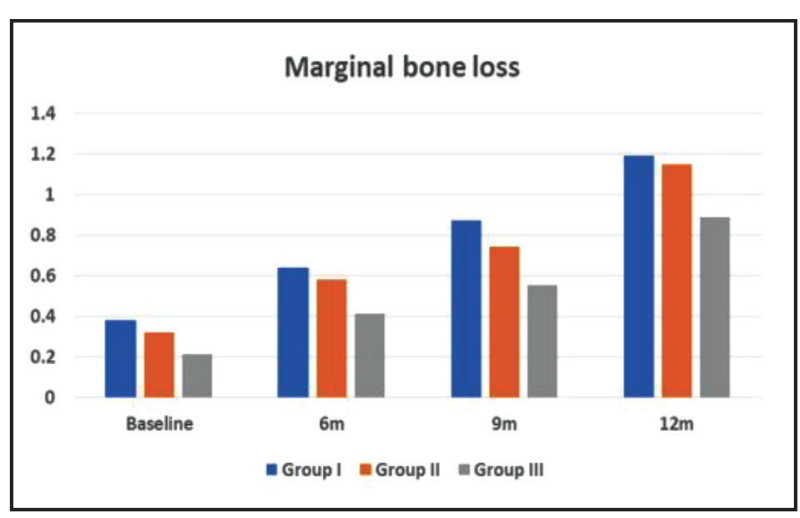

Figure (2): Bar chart representing Marginal bone loss values for different groups

\section{DISCUSSION}

Implant placement has been a renowned treatment modality for replacing and restoring missing teeth in recent past. In 1965 Branemark placed the first endosteal titanium implant successfully. He placed the implant in edentulous ridge of the patient. Delayed implant placement signifies the placement of the implant in the healed extracted socket after a minimum of 5-6 months ${ }^{(14)}$.

All patients selected undergone CBCT. Scan \& periapical radiography for treatment planning; this in accordance with authors who ${ }^{(15)}$ mentioned that , radiographic evaluation is an important tool in dental implant for cases selection, treatment planning, during surgical procedures to determine drilling location without endangering the anatomical structures such as the mandibular alveolar nerve, during prosthetic procedures when evaluating the position of abutments or superstructures and for evaluation of the marginal bone level in follow-up sessions.

It is important to note that, selection of suprastructure materials for Implant-abutment complex is of important concern as it directly affects the health of periodontal tissues around dental implant. In the current study, three types of all ceramic superstructure materials were used; monolithic zirconia, Zirconia reinforced lithium silicate Ceramics and Polymer infiltrated glass ceramics. 
Zirconia is an excellent choice for many prosthetic cases owing to its good chemical properties, biocompatibility, mechanical properties and good esthetic ${ }^{(16)}$. Delamination or chipping of the veneering material was the most common problem reported with bi-layered zirconia due to the low bond strength between veneering materials and zirconia frameworks. A new formulation of (Y-TZP) has been introduced to be used in full contour configuration in an attempt to minimize chipping of veneering Porcelain.

Zirconia reinforced lithium-silicate- ceramic (ZLS) is a newly introduced dental material. The material has a flexural strength of $420 \mathrm{MPa}$ and good surface finishing and polishing as the zirconia particles are small and homogeneously distributed throughout the glassy matrix.This material is available in a machinable blocks to be used for a wide variety of prosthetic devices, and to the present date, no enough data have yet been available about using this product as an implant superstructure ${ }^{(17)}$.

VITA Enamic from VITA, have two 3dimensional network structures interpenetrating one to another; the dominant fine-structure which is feldspar ceramic network is strengthened by a polymer network consisting of methacrylate polymer ( $14 \%$ by weight or $25 \%$ by volume). The flexural strength of such two-phase material could reach a value of about $150-160 \mathrm{MPa}$ which is significantly higher than that of a porous ceramic (below $30 \mathrm{MPa}$ ) and polymer (135 MPa) alone ${ }^{(18)}$. Fracture toughness, hardness and elastic modulus values are as follows: $1.72 \mathrm{MPa} \cdot \mathrm{m}^{-0.5}, 2.59 \mathrm{GPa}$ and $30.14 \mathrm{GPa}$ respectively ${ }^{(19)}$, all of them between those of human enamel and dentin. Vita Enamic has the highest Vickers hardness of $189 .{ }^{(20)}$ owing to the highest filler content (73.1 mass \%) compared to other hybrid ceramics and composites. Moreover, VITA Enamic has similar two-body and toothbrushing wear characteristic to natural enamel (21). All these features particularly, low modulus of elasticity number nominated those materials to be used as an implant suprastructures that will allow for better distribution of occlusal forces on the implant component system.

The modified plaque index (MPI) was used in this study to assess the patient oral care and hygiene in a quantitatively. A study observed over a 6 years period ${ }^{(22)}$ found a direct relationship between plaque accumulation and bone resorption around dental implant. In present study, the mean modified plaque index (MPI) in all groups during the observation period indicated minimal plaque accumulation around the implants and good oral hygiene practices by the patients as there were no statistically significant alterations throughout the time intervals.

Some authors ${ }^{(23)}$ stated that bleeding on probing has high specificity but low sensitivity meaning that its absence indicates disease stability. In the current study, the mean modified bleeding index (MBI) was not reach 0.6 (The highest mean of MBI was 0.57 ) at end of the observation period in all groups indicated minimal inflammation and tissue stability around the implants as no statistically significant alterations throughout the time intervals was found.

Loss of marginal bone to a limited degree is considered a normal phenomenon to reestablish the biologic width a round dental implant ${ }^{(24)}$. Therefore, 1 year after superstructure placement in the current study, marginal bone level measurements were $1.19 \mathrm{~mm}, 1.15 \mathrm{~mm} \& 0.89 \mathrm{~mm}$ in the three studied groups respectively which is considered part of the normal healing.

By the end of this study, group I and group II showed more pronounced marginal bone loss (1.19 $\mathrm{mm}$ and $1.15 \mathrm{~mm}$ respectively) while group III showed less marginal bone loss $(0.89 \mathrm{~mm})$ at 12 months. It hypothesized that group III showed a less value of marginal bone loss (MBL) than other groups at 12 months because of favorable mechanical behavior of final prosthesis in terms of better stress distribution pattern due to low elastic modulus number. This finding was similar to a study (25) concluded that a rigid superstructure materials 
transfer greater load to implant and supporting bone. While, on the other hand, prosthesis constructed of a low elastic modulus materials transfers less loading to implant and supporting bone.

This study was in agreement with another study (26) evaluated the stress distribution on implant supported FPD constructed of metal ceramic and fiber reinforced composite. The study reported that fiber reinforced composite reduces the load value transmitted to the abutment-fixture complex and that in turn decreases the stress transferred to supporting structure and minimizes the risk of peri implant bone resorption.

The present study wasn't in agreement with a study (27) used 3-D FEA to investigate the stress induced in both bone and implant-abutment with three different superstructure materials (gold, porcelain and composite) for a 3-unit implant supported bridge. That study demonstrated that the type of superstructure materials doesn't affect the stress distribution pattern on both implant-abutment complex and the supporting bone.

Another study (28) investigated the effect of two superstructure materials (metal and acrylic resin) on load distribution on implant supported cantilever bridges. The study reported a better stress distribution pattern with metal superstructure when compared to acrylic resin which wasn't in agreement with the present study.

Finally, the clinical interests are increasingly focusing on stability and long term stability of dental implant that will withstand dynamic loading. This would require a new bone formation around implant and selection of suprastructure material may be an essential factor. In the present study, the capabilities of suprastructure materials to minimize the risk of peri-implant periodontal tissue destruction was obvious, validating the hypothesis that the careful selection of suprastructure materials will enhance osseointegration and stability of dental implant.

\section{CONCLUSIONS}

1. Modified Plaque and Bleeding indices are periodontal parameters mainly influenced by the patient oral care and oral hygiene instructions provided that the implant suprastructure materials are highly polished and well adapted to abutment margin.

2. Less MBL values were reported with zirconia suprastructures followed by zirconia reinforced lithium silicate and polymer infiltrated glass ceramic as the last two materials maintain a more favorable load distribution pattern in the surrounding bone and decreases the risk of marginal bone resorption around dental implant.

3. Polymer infiltrated glass ceramic may be a good choice as a superstructure material for implant supported dental prosthesis when compared to other rigid materials such as metals and ceramics.

\section{REFERENCES}

1. Culhaoglu AK, Ozkir SE, Celik G, Terzioglu H. Comparison of two different restoration materials and two different implant designs of implant-supported fixed cantilevered prostheses: A 3D finite element analysis. Eur J Gen Dent. 2013;2:144-50.

2. Pathak AK, Goel K, Shakya V, Tiwari AK. Periodontal parameters around implants and natural teeth. Nat J Maxillofac Surg. 2016;7:52-5.

3. Esposito $\mathrm{M}$, Worthington $\mathrm{HV}$, Coulthard $\mathrm{P}$, Thomsen P. Maintaining and reestablishing health around osseointegrated oral implants: a Cochrane systematic review comparing the efficacy of various treatments. Periodontol. 2000. 2003;3:204-12.

4. Rezende CEE, Chase Diaz M, Costa MD, Albarracin ML, Paschoeto G, Sousa EAC, et al. Stress distribution in single dental implant system: three dimensional finite element analysis based on an in vitro experimental model. J Craniofac. Surg. 2015;26:2196-200.

5. Rubo JH, Capello Souza EA. Finite element analysis of stress on dental implant prosthesis. Clin implant Dent Relat Res. 2010;12:105-13. 
6. Junior JFS, Pellizzer EP, Verri FR, de Carvalho PSP. Stress analysis in bone tissue around single implants with different diameters and veneering materials: a $3 \mathrm{D}$ finite element study. Mater Sci Eng C. 2013;33:4700-14.

7. Grando AF, Rezende CEE, Sousa EAC, Rubo JH. Effect of veneering material on the deformation suffered by implant-supported fixed prosthesis framework. J Appl Oral Sci 2014;22:209-17.

8. Oh TJ, Yoon J, Misch CE, Wang HL. The causes of early implant bone loss: myth or science? J Periodontol. 2002;73:322-33.

9. Çiftçi Y. The effect of veneering materials on stress distribution in implant supported fixed prosthetic restorations. Int J Oral Maxillofac Surg. 2000;15: 571-82.

10. Conserva E, Menini M, Tealdo T, Bevilacqua M, Ravera $\mathrm{G}$, Pera F, et al. The use of a masticatory robot to analyze the shock absorption capacity of different restorative materials for prosthetic implants: a preliminary report. Int J Prosthodont. 2009;22:53-5.

11. El-Anwar MI, El-Mofty MS, Awad AH, El-Sheikh SA, El-Zawahry MM. The effect of using different crown and implant materials on bone stress distribution: a finite element study. Egy J Oral Maxillofac Surg. 2014;5:58-64.

12. Geraets W, Zhang L, Liu Y, Wismeijer D. Annual bone loss and success rates of dental implants based on radiographic measurements. Dentomaxillofac Radiol. 2014; 43:20140007

13. Mombelli A, Lang NP. Clinical parameters for the evaluation of dental implants. Periodontol 2000. 1994;4:81-6.

14. Ebenezer V, Balakrishnan Ramalingam SP, Mohan MR, Muthumani T. Immediate Implant vs Delayed Implant Placement. A Review of 100 Cases. Biosci Biotechno Res Asia. 2014;11:937-40

15. De Bruyn H, Vandeweghe S, Ruyffelaert C, Cosyn J, Sennerby L. Radiographic evaluation of modern oral implants with emphasis on crestal bone level and relevance to peri-implant health. Periodontolo 2000. 2013;62:256-70.

16. Ahmad I. Yttrium partially stabilized zirconium dioxide posts: an approach to restoring coronally compromised nonvital teeth. Int J Periodontics Restorative Dent. 1998;18:454-65.

17. de Carvalho Ramos N, Campos TMB, de La Paz IS, Machado JPB, Bottino MA, Cesar PF, et al. Microstructure characterization and SCG of newly engineered dental ceramics. Dent Mater. 2016;32:870-8.
18. Coldea A, Swain MV, Thiel N. Mechanical properties of polymer infiltrated ceramic network materials. Dent Mater. 2013;29:419-26.

19. He L-H, Swain M. A novel polymer infiltrated ceramic dental material. Dent Mater. 2011;27:527-34.

20. Lauvahutanon S, Takahashi H, Shiozawa M, Iwasaki $\mathrm{N}$, Asakawa Y, Oki M, et al. Mechanical properties of composite resin blocks for CAD/CAM. Dent mater J. 2014;33:705-10.

21. Mörmann WH, Stawarczyk B, Ender A, Sener B, Attin T, Mehl A. Wear characteristics of current aesthetic dental restorative CAD/CAM materials: two-body wear, gloss retention, roughness and Martens hardness. J Mech Behav Biomed Mater. 2013;20:113-25.

22. Stefan A. Hienz, Paliwal S, Ivanovski S. Mechanisms of Bone Resorption in Periodontitis. J Immunol Res. 2015; 2015: 615486

23. Checchi L, Montevecchi M, Checchi V, Zappulla F. The Relationship Between Bleeding on Probing and Subgingival Deposits. An Endoscopical Evaluation. Open Dent J. 2009; 3: 154-60.

24. Hermann JS, Buser D, Schenk RK, Higginbottom FL, Cochran DL. Biologic width around titanium implants. A physiologically formed and stable dimension over time. Clin Oral implants Res. 2000;11:1-11.

25. Sevimay M, Usumez A, Eskitascioglu G. The influence of various occlusal materials on stresses transferred to implant supported prostheses and supporting bone: a three dimensional finite element study. J Biomed Mater Res B Appl Biomater. 2005;73:140-147.

26. Erkmen E, Meriç G, Kurt A, Tunç Y, Eser A. Biomechanical comparison of implant retained fixed partial dentures with fiber reinforced composite versus conventional metal frameworks: a 3D FEA study. J Mech Behav Biomed Mater. 2011;4:107-16.

27. Stegaroiu R, Kusakari H, Nishiyama S, Miyakawa O. Influence of prosthesis material on stress distribution in bone and implant: a 3 dimensional finite element analysis . Int J Oral Maxillofac Implants. 1998;13:781-90.

28. Duyck J, Van Oostenvyck H, Vander Sloten J, De Cooman M, Puers R, Naert I. Influence of prosthesis material on the loading of implants that support a fixed partial prosthesis: in vivo study. Clin Implant Dent Relat res. 2000;2:100-9. 